\title{
Evaluation of fitness in implant screw as tightening torque in dental laboratory
}

\author{
Young-Gyun Song* \\ Department of Prosthodontics, College of Dentistry, Dankook University, Cheonan, Republic of Korea
}

Purpose: The purpose of this study was to measure the tightening torque for dental implant in dental laboratory and to analyze of the effects of different tightening torque. Materials and Methods: The tightening torque for dental implant in dental laboratory were measured by digital torque gauge. The length of abutment and analog were measured as tightening torque of manufacturer's instructions and the measured value. And the data were statically analyzed. Results: The mean tightening torque of implant screw in dental laboratory was $1.563 \pm 0.332 \mathrm{Ncm}$. The external type implant system of total length were showing no significant differences but the internal type implant system had difference significant $(P<0.05)$ when compared with tightening torque. Conclusion: The implant prosthesis should be made under manufacturer's instructions especially as tightening torque of screw. For the fidelity of implant prosthesis, dental technician should learn how to use the torque gauge. (J Dent Rehabil Appl Sci 2015;31(4):310-5)

Key words: implant torque controller; dental technician; implant-abutment; settlement

\section{서론}

임플란트가 치과영역에서 사용된 이후, 임플란트 고정 체의 모양과 표면 그리고 지대주와의 체결방식 등이 다 양하게 연구되고 발전되어왔다. 대한민국에서는 이제 임 플란트 보철치료도 일부 급여화가 되면서 그 수요가 더 욱 늘어났다. 치과보철과 영역에서 기존의 계속가공의치 나 가철성 보철물과 더불어 임플란트를 이용한 수복이 많은 부분을 차지하고 있다. 임플란트는 치아와는 다르 게 치주인대의 부재와 치근보다 작은 직경으로 인해 생 역학적 고려뿐만 아니라, 치아를 이용한 수복물보다 더 정밀한 기공과정을 요구한다. 치조골에 유착된 임플란트 는 약간의 동요나 유격을 허용하지 않는다. 때문에 기공
과정에서 구강 내와 가장 유사한 환경이 필요하다.

임플란트의 제조회사별로 다르지만, 대부분의 회사의 경우 임플란트 고정체와 지대주의 체결 토크는 20 - 30 $\mathrm{Ncm}$ 로 설정되어 있다. 구강 내 환경과 유사한 상태로 기 공작업을 진행하기 위해서는 구강 내에서 체결하는 토크 와 동일한 토크로 기공과정이 이루어져야 하지만, 대부 분의 치과기공실에서 토크드라이버를 갖추고 기공하는 경우는 극히 드문 경우이다. ${ }^{1}$

이번 연구에서는 토크 게이지를 이용하여, 일반적으로 치과치과 치과 기공사들이 임플란트 기공을 진행 때 가 해지는 토크의 양을 측정해 분석하고, 이러한 결과가 보 철물에 어떠한 결과를 미치는 알아보기 위함이다.

Copyright@ 2015 The Korean Academy of Stomatognathic Function and Occlusion. (c) It is identical to Creative Commons Non-Commercial License. 


\section{연구 재료 및 방법}

\section{1. 연구 재료}

내부 연결형과 내부 연결형 임플란트의 직경 $4 \mathrm{~mm}$ 의 $\operatorname{analog}(\mathrm{Lab}$ analog [IS system \& EB system], Neobiotech, Seoul, Korea)와 티타늄 지대주(Hex abutment [IS system \& EB system], Neobiotech)를 사 용하였다(Fig. 1). 최고 토크를 측정하기 위해 디지털 토 크 게이지(HTG2-200Nc, IMADA, Toyohashi, Japan) 를 사용하였으며, 측정된 치과 치과 기공사들의 평균 토크로 나사를 체결하기 위해 렌치형 토크게이지를 사 용하였다. 침하량 측정을 위해서 디지털 마이크로미터 (Micrometer IP65, Mitutoyo, Kanagawa, Japan)를 사용 하였다.

\section{2. 치과 기공사들의 조임토크 측정}

현직에 근무하면서 치과임플란트 기공을 하고 있는 치과 기공사 15 명을 대상으로 임플란트 기공물의 임플 란트 나사를 평소 조이는 방식으로 연속으로 3번 조인 후에 디지털토크게이지에 장착된 핸드 드라이버를 돌 려, 토크의 최대치를 측정하였다(Fig. 2). 같은 방식으로 3 회 반복 측정하여 총 45 회의 측정값을 측정하였다.

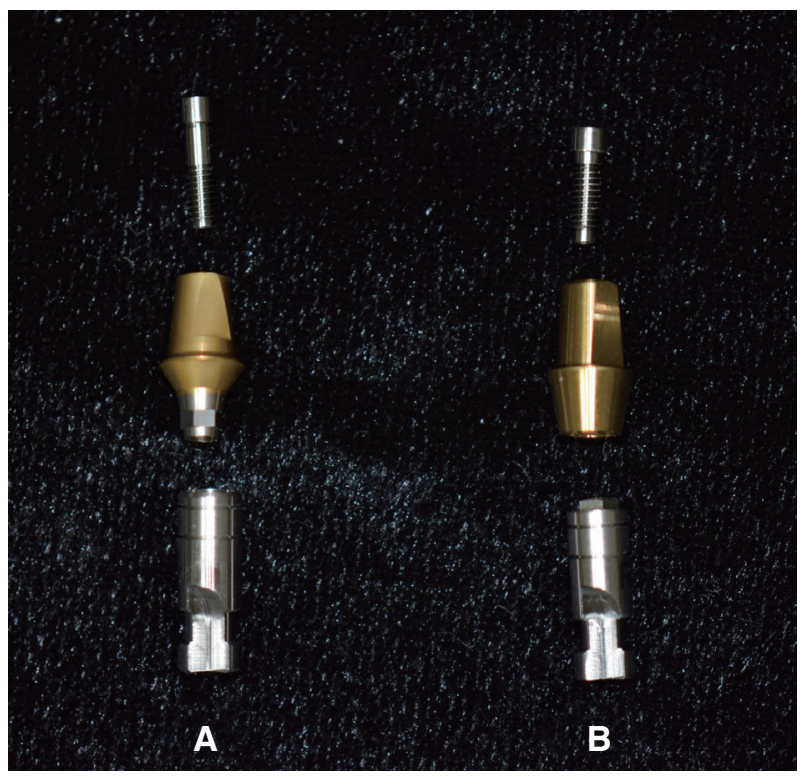

Fig. 1. Implant abutment and analog (A) internal type, (B) external type.

\section{3. 임플란트 침하량 측정}

1) 제조사 지침에 따른 토크시 침하량 측정

임플란트 analog와 지대주를 외부연결형과 내부 연 결형 각 4개씩 총 8 개를 준비하였다. Analog를 탁상용 바이스와 고무완충재를 이용하여 고정한 뒤, 제조사의 지침에 따라 토크 드라이버를 이용하여, $30 \mathrm{Ncm}$ 힘으 로 지대주를 체결하였다. 지대주를 체결한 뒤 지대주와 $\operatorname{analog}$ 의 총 길이를 디지털 마이크로미터를 이용하여 측정하였다(Fig. 3). 하나의 지대주당 5회 반복하였으며, 총 40 회의 측정을 시행하였다.

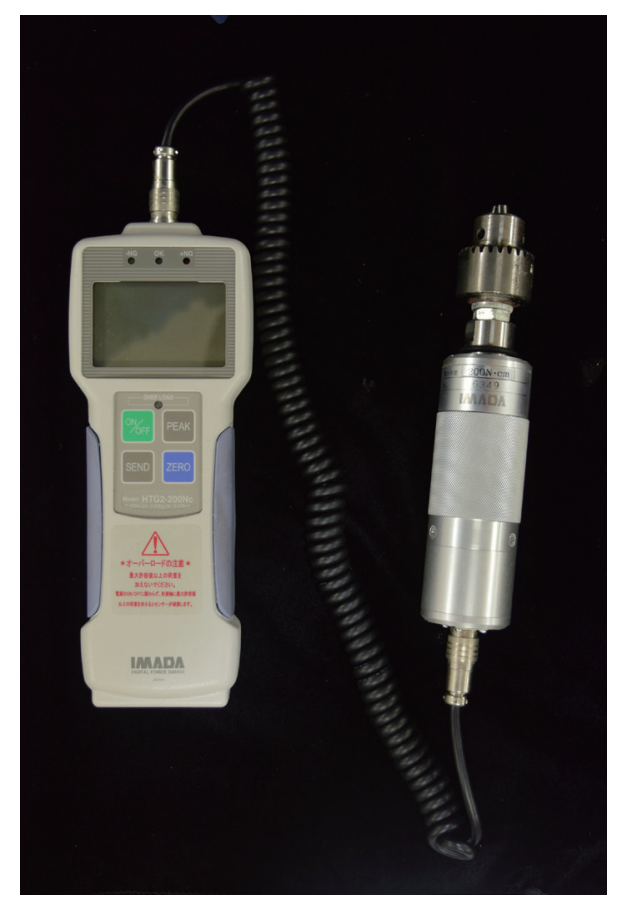

Fig. 2. Digital torque gauge used in this study.

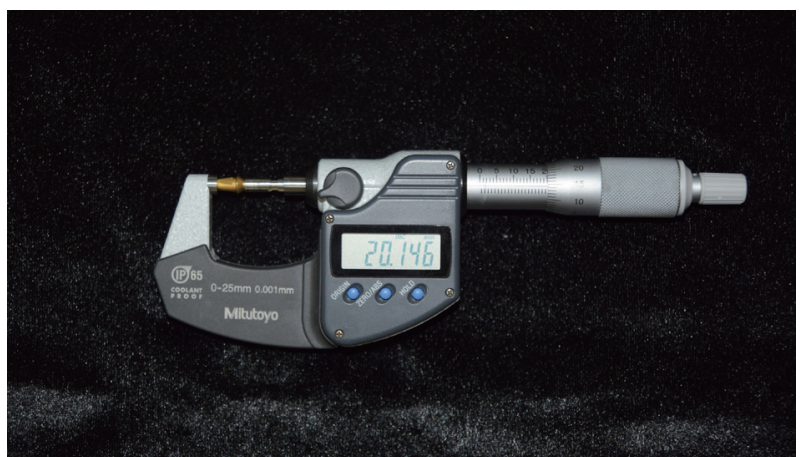

Fig. 3. Measurement of implant-abutment length. 
2) 치과 기공사의 평균 토크에 따른 침하량 측정

새로운 임플란트 analog와 지대주를 외부연결형과 내 부 연결형 각 4 개씩 총 8 개를 준비하였다. 토크 게이지 를 이용하여 렌치형 토크드라이버를 기공시 실제로 이 루어지는 토크로 보정하였다. 토크 드라이버를 이용하 여 임플란트 나사를 체결한 뒤 지대주와 analog를 체결 하여, 디지털 게이지를 이용하여, 지대주와 analog의 총 길이를 측정하였다. 하나의 지대주당 5 회 반복하였으며, 총 40 회의 측정을 시행하였다.

\section{4. 통계분석}

통계는 IBM SPSS 19 (IBM, Chicago, USA)를 이용하 여 분석하였다. 연결방식에 따른 지대주침하량을 비교 하기 위해 Wilcoxon rank sum test를 사용하여 유의수 준 $P=0.05$ 에서 평가하였다.

\section{결과}

\section{1. 치과 기공사들 평균 토크}

치과 기공사들이 실제로 기공시 사용하는 수작업 토 크를 디지털토크로 측정한 결과 평균 $1.563 \pm 0.332$ $\mathrm{Ncm}$ 로 나타났다. 일부 치과 기공사의 경우 매우 낮은 토크를 사용하였는데, 일반적으로 제조사가 추천하는 토크를 가하기 위해서는 토크렌치 등이 필요하나 조사 한 치과 기공사들 중 토크렌치 등을 사용하는 치과 기공 사는 없었다(Table 1).

\section{2. 토크에 따른 침하량}

치과 기공사들이 사용하는 평균 토크와 제조사에서 추천하는 토크로 임플란트 나사를 체결하였을 때, 지대 주에서 analog까지의 길이는 통계적으로 유의한 차이를 보였다 $(P<0.05)$. 침하량을 계산한 결과 외부연결형은 침하량의 차이가 통계적으로 유의한 차이가 없었으며, 내부연결형에서는 침하량의 차이가 통계적으로 유의하 게 나타났다 $(P<0.05$, Table 2 , Fig. 2$)$.

\section{고찰}

임플란트의 상부 보철물의 부적합으로 인한 부작용 은 자연치를 수복하는 경우와는 다르지만, 나사풀림 등 의 기계적 합병증의 원인이 된다. ${ }^{2-5}$ 일반적으로 내부경 사구조를 가진 내부연결형에서는 조임토크에 따른 침

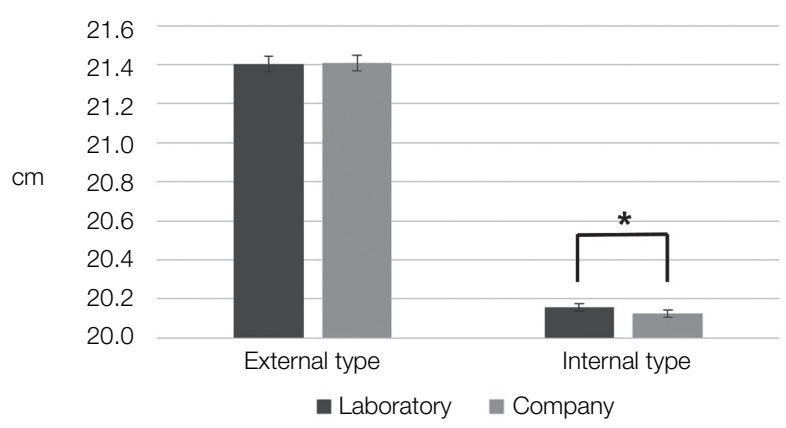

Fig. 4. Comparison of total Length of abutment type and tightening torque.

* Denote difference significant at 0.05 values.

Table 1. Tightening torque of implant screw in dental laboratory

(Unit: $\mathrm{Ncm}$ )

\begin{tabular}{ccccc}
\hline Number & Maximum vale & Minimum vale & Mean & Standard deviation \\
\hline 45 & 0.630 & 2.040 & 1.563 & 0.332 \\
\hline
\end{tabular}

Table 2. Total length of abutment and analog as tightening torque of implant screw

(Unit: cm)

\begin{tabular}{cccc}
\hline Group & Abutment type & Mean & Standard deviation \\
\hline Laboratory & External type & 21.401 & 0.041 \\
& Internal type & 20.158 & 0.019 \\
Company & External Type & 21.407 & 0.041 \\
& Internal Type & 20.124 & 0.019 \\
\hline
\end{tabular}


하량의 차이가 있다. ${ }^{6}$ 제조사가 추천하는 토크로 임플란 트 나사를 체결한 경우에도 내부 연결형 임플란트에서 는 하중에 의한 침하가 일어난다고 보고되고 있다. ${ }^{7}$ 치 과 기공사들의 경우 임플란트 기공시 임플란트 나사 체 결을 강하게 하지 않는 이유로 기공의 편이성과 임플란 트 나사헤드의 마모 등을 꼽았다. 또한 핸드 드라이버로 체결할 수 있는 토크에 제한이 있기 때문에, 별도로 토 크 렌치를 구비하지 않은 경우 제조사의 추천에 따른 토 크로 체결이 불가능할 것으로 사료된다.

외부연결형의 지대주는 치근형 임플란트가 상용화되 기 시작하면서부터 많이 사용되어 왔으나, 내부 연결형 의 방식이 결합부의 안정성 및 고정체의 응력분산에 더 좋다는 보고와 나사풀림이 적게 나타나기 때문에 재료 나 형태의 영향을 적게 받는다는 보고에 따라 최근에는 내부 연결형의 임플란트가 많이 사용되고 있다. ${ }^{8-10}$ 그러 나 이전의 연구에서와 동일하게 이번 연구에서 내부 연 결형 임플란트시스템의 경우 토크에 따른 침하량의 차 이를 보였고, 외부 연결형의 경우 토크에 따른 침하량 의 차이는 보이지 않았다. 이것은 내부 연결형 임플란트 의 경우 임플란트 나사체결 토크 및 지대주 침하요인에 대한 주의가 더 필요하다는 것을 의미하며, 내부 연결형 임플란트가 부를 이루는 요즘 기공에 더 주의를 기울려 야 할 것이라 사료된다.

보철물의 방식에 따라 차이가 있겠지만, 침하량의 차 이는 여러 가지 문제를 야기할 수 있다. 단일치의 임플 란트의 경우 저위교합의 문제점을 일으킬 수 있으며, cemented type의 경우 자연 치와 같이 치아우식증과 같 은 합병증은 발생하지 않지만, 보철물 부적합으로 인한 하중의 부조화로 인해 나사의 풀림이나, 파절을 초래할 수 있다. ${ }^{11,12}$ 이러한 부적합은 서로 평행하지 않은 두 개 이상의 임플란트 보철물에서 더 심하게 나타날 수 있다. 서로 평행한 임플란트의 토크차이로 인한 수직적 침하 량 차이는 보철물에서 수직적인 문제만을 일으키지만, 평행하지 않은 두 개 이상의 임플란트의 경우, 수직적인 문제뿐만 아니라 수평적인 오차로 인해 임플란트의 수 평적 피로를 증가시킬 수 있다. 수평적인 힘에 취약한 임플란트의 생역학적 특성상 저작에 의한 수평적 힘이 아닌 지속적으로 발생하는 수평적인 힘은 임플란트의 성공율에도 영향을 미칠 수 있다.

이 실험에서는 조임토크 실험에서 5 회까지는 임플란 트 나사의 교체 없이 진행하였는데, 치과용 임플란트의 임플란트 나사의 경우 추천 체결토크값이 항복강도의
$75 \%$ 이내에서 정해진다는 보고에 따라 5 회까지는 임플 란트 나사의 교체 없이 실험을 진행하였다. ${ }^{13}$

적정토크의 경우, 토크 조절기를 이용하여야 하는데, 토크 조절기의 경우도 관리에 따라서 많은 차이가 난다 는 보고가 있다. 특히 임상에서 사용하는 토크 조절기의 경우 토크값이 높은 경우보다 낮은 경우가 약 4배 정도 높게 나타난다는 결과가 보고되었기 때문에 토크조절기 를 사용하여 기공에 임했다고 하더라도, 실제로 부여된 토크는 의도한 토크값보다 낮을 수 있다. 따라서 정확한 토크값의 부여를 위해 주기적인 관리 및 보정이 필요하 다. ${ }^{14}$ 또한 적정토크를 부여하기 위해서는 일정한 토크 를 부여할 수 있도록 임상가의 숙련이 필요하다. 숙련되 지 않은 임상가의 경우 적절한 기구가 있더라도 적절한 토크를 부여할 수 없는 경우가 발생할 수 있다..$^{15} \mathrm{Tan}$ 과 Nicholls ${ }^{16}$ 는 구강외과의사들은 적정토크값보다 낮은 토 크값을 보이고, 심지어 보철과 의사들도 $15 \%$ 내에서 토 크값의 오차를 보인다고 하였다. 또한 나사를 조이는 속 도에 따른 차이도 나타나는데, Standlee와 Caputo ${ }^{17}$ 는 나 사를 $5.2 \mathrm{Ncm} / \mathrm{sec}$ 로 조였을 때에 비해, $16.4 \mathrm{Ncm} / \mathrm{sec}$ 로 빠르게 조였을 때 조임력이 더 작게 나타났다고 보 고하였다. 또한 여러 가지 종류의 토크 조절기중에서 Latch type의 토크 조절기가 임상적으로 더 유용하다고 한다. ${ }^{18}$ 따라서 치과기공실과 진료실에서 임플란트에 가 하는 토크의 차이를 줄이기 위해서는 동일한 토크 조절 기를 사용하는 것뿐만 아니라, 치과 기공사와 임상가 모 두 의도한 적정 토크를 가하기 위해 숙련된 기술이 필요 할 것이라 사료된다.

본 실험의 경우, 적은 표본으로 단순히 치과기공실에 서 이루어지는 토크를 비교한 것이다. 실제로 진료실에 서 정확한 토크값이 부여된다는 조건하에 실험이 이루 어졌으며, analog와 고정체가 동일한 조건으로 간주하 고 진행된 한계점이 있기 때문에 향후 추가적인 연구가 필요할 것으로 사료된다. 그러나 실제로 치과 기공사들 의 임플란트 기공시 임플란트 나사토크를 측정한 논문 이 거의 없다는 점에서 의의가 있다고 사료된다. 본 연 구를 바탕으로 하였을 때, 부정확한 위치에서 시행한 기 공의 경우 모델에서 적합도가 좋다고 하더라도, 환자에 게 장착된 후에는 좋은 기공물이라고 하기 어렵다. 이러 한 오차를 줄이기 위해, 임플란트 기공시 치과 기공사는 제조사의 추천 체결 토크에 대한 인지와 함께 토크게이 지를 이용한 기공을 시행하여야 할 것으로 사료된다. 


\section{결론}

치과 보철물에서의 기공오차는 여러 가지 원인에 의 해 일어날 수 있으며, 특히 임플란트 기공물의 오차는 자연치아에서의 오차보다 더 적은 오차만을 허용해야 한다. 이러한 오차의 원인 중 나사의 토크값에 따른 차 이를 연구한 결과 다음과 같은 결론을 얻었다.

치과 기공사들이 임플란트 기공시, 나사에 부여하는 평균 토크값은 $1.563 \pm 0.332 \mathrm{Ncm}$ 이다.

적정토크값과 치과 기공사가 부여하는 토크값에서의 침하량은 차이가 있었다.

외부연결형의 경우 토크값에 따른 침하량에 통계적 유의성이 없으나, 내부 연결형의 경우 통계적 유의 성이 나타났다.

\section{Acknowledgements}

이 연구는 2014학년도 단국대학교 대학연구비 지원으 로 연구되었음.

\section{ORCID}

Young-Gyun Song http://orcid.org/0000-0003-3789-9585

\section{References}

1. Artzi Z, Dreiangel A. A screw lock for single-tooth implant superstructures. J Am Dent Assoc 1999; 130:677-82.

2. Schwarz MS. Mechanical complications of dental implants. Clin Oral Implants Res 2000;11:156-8.

3. Cavazos E, Bell FA. Preventing loosening of implant abutment screws. J Prosthet Dent 1996;75: 566-9.

4. Kang YM, Lim JH, Cho IH. A study on the abutment screw loosening of dental implants. J Korean Acad Prosthodont 1996;34:1-14.

5. Im SM, Kim DG, Park CJ, Cha MS, Cho LR. Biomechanical considerations for the screw of implant prosthesis: A literature review. J Korean Acad Prosthodont 2010;48:61-8.

6. Dailey B, Jordan L, Blind O, Tavernier B. Axial displacement of abutments into implants and implant replicas, with the tapered cone-screw internal con- nection, as a function of tightening torque. Int $\mathrm{J}$ Oral Maxillofac Implants 2009;24:251-6.

7. Siamos G, Winkler S, Boberick KG. Relationship between implant preload and screw loosening on implant-supported prostheses. J Oral Implantol 2002;28:67-73.

8. Maeda Y, Satoh T, Sogo M. In vitro differences of stress concentrations for internal and external hex implant-abutment connections: a short communication. J Oral Rehabil 2006;33:75-8.

9. Khraisat A, Stegaroiu R, Nomura S, Miyakawa O. Fatigue resistance of two implant/abutment joint designs. J Prosthet Dent 2002;88:604-10.

10. Norton MR. An in vitro evaluation of the strength of a 1-piece and 2-piece conical abutment joint in implant design. Clin Oral Implants Res 2000;11: 458-64.

11. McGlumphy EA, Mendel DA, Holloway JA. Implant screw mechanics. Dent Clin North Am 1998; 42:71-89.

12. Burguete RL, Johns RB, King T, Patterson EA. Tightening characteristics for screwed joints in osseointegrated dental implants. J Prosthet Dent 1994;71:592-9.

13. Choi JH, Yang JH, Cho WP, Lee JB. The influence of abutment screw length and repeated tightening on screw loosening in dental implant. J Korean Acad Prosthodont 2006;44:432-42.

14. Joo YH, Lee JH. A study on accuracy and application of the implant torque controller used in dental clinic. J Korean Acad Prosthodont 2011;49:197205.

15. Jaarda MJ, Razzoog ME, Gratton DG. Providing optimum torque to implant prostheses: a pilot study. Implant Dent 1993;2:50-2.

16. Tan KB, Nicholls JI. The effect of 3 torque delivery systems on gold screw preload at the gold cylinder-abutment screw joint. Int J Oral Maxillofac Implants 2002;17:175-83.

17. Standlee JP, Caputo AA. Accuracy of an electric torque-limiting device for implants. Int J Oral Maxillofac Implants 1999;14:278-81.

18. Huh YH, Cho LR, Kim DG, Park CJ. Comparison of Implant Torque Controllers using Detorque Value. J Dent Rehabil Appl Sci 2010:26:419-32. 


\section{기공실에서의 임플란트 토크값에 따른 적합도 평가}

\section{송영균}

단국대학교 치과대학 치과보철학교실

목적: 본 연구는 토크 게이지를 이용하여, 치과 기공사들이 임플란트 기공을 진행할 때 가하는 토크의 양을 측정해 분 석하고, 이러한 결과가 보철물에 어떠한 결과를 미치는 알아보기 위함이다.

연구 재료 및 방법: 치과 기공사들이 임플란트 기공시 임플란트 나사에 가하는 토크를 디지털 토크 게이지를 이용하여 측정한다. 이후 기성지대주와 $\operatorname{analog}$ 를 이용하여, 제조사의 권장 토크로 조였을 때의 길이를 통계학적으로 비교 분석 하였다.

결과: 치과 기공사들의 임플란트 기공시 평균 토크는 $1.563 \pm 0.332 \mathrm{Ncm}$ 로 나타났으며, 제조사의 권장토크 값으로 조 였을 때와 비교하면, 외부연결형의 침하량 차이는 없으나, 내부연결형의 침하량의 차이는 통계적으로 유의한 차이를 보였다 $(P<0.05)$.

결론: 치과기공실에서도 제조사의 권장토크를 이용하여 보철물 기공작업을 시행하고, 정확한 토크 게이지의 사용법을 익히면, 기공오차에 따른 임플란트의 부적합을 어느 정도 해소할 수 있을 것이라 사료된다.

(구강회복응용과학지 2015;31 (4):310-5)

주요어: 임플란트 토크조절기; 치과 기공사; 임플란트-지대주; 침하량 